\title{
Numerical Analysis of Soil Slope Stabilization by Soil Nailing Technique
}

\author{
Dildar Ali Mangnejo \\ Department of Civil Engineering \\ Mehran University, \\ Shaheed Zulfiqar Ali Bhutto Campus \\ Khairpur Mir's, Sindh, Pakistan \\ dildarali72@gmail.com
}

\author{
S. Ahmed \\ Department of Civil Engineering \\ Mehran University, \\ Shaheed Zulfiqar Ali Bhutto Campus \\ Khairpur Mir's, Sindh, Pakistan \\ sajeelahmed16@gmail.com
}

\author{
S. J. Oad \\ Department of Civil Engineering \\ Technology, The Benazir Bhutto \\ Shaheed University of Technology and \\ Skill Development, Pakistan \\ shamotra@bbsutsd.edu.pk \\ F. H. Laghari \\ Department of Civil Engineering \\ Mehran University, \\ Shaheed Zulfiqar Ali Bhutto Campus \\ Khairpur Mir's, Sindh, Pakistan \\ faizanhyder22@hotmail.com
}

\author{
Shahbaz Ali Kalhoro \\ Department of Civil Engineering \\ Mehran University, \\ Shaheed Zulfiqar Ali Bhutto Campus \\ Khairpur Mir's, Sindh, Pakistan \\ abbasishahbazkhan@yahoo.com \\ Z. A. Siyal \\ Department of Civil Engineering \\ Mehran University, \\ Shaheed Zulfiqar Ali Bhutto Campus \\ Khairpur Mir's, Sindh, Pakistan \\ zameersiyal@yahoo.com
}

\begin{abstract}
Slope instability may be a result of change in stress conditions, rise in groundwater table and rainfall. Similarly, many slopes that have been stable for several years can abruptly fail due to changes in geometry, weak soil shear strength or as an external forces effect. Debris flows (i.e. slope failures) take place without any warning and can have devastating results. So, it is vital to understand the slope failure mechanism and adopt safety prevention measures. Soil nailing is one of the widely used stabilization techniques for soil slopes. In this study, soil nail technique is proposed to upgrade the existing slope in clay. A parametric study was conducted to understand the effects of different nail diameter (i.e. $25 \mathrm{~mm}$ and $40 \mathrm{~mm}$ ) and nail inclination (i.e. $20^{\circ}, 25^{\circ}, 30^{\circ}, 35^{\circ}$ and $40^{\circ}$ ) on slope stability. MorgensternPrice (i.e. limit equilibrium) method was used to determine the factor of safety of the slope. It was found that the factor of safety of the existing slope improved significantly with three rows of $40 \mathrm{~mm}$ diameter nail at inclination of $40^{\circ}$.
\end{abstract}

Keywords-slope stability; soil nail technique; nail diameter and inclination

\section{INTRODUCTION}

Slope instability problems in natural and man-made slopes constitute some the most usual challenges for civil engineers. Slope instability may be the result of changes in stress conditions, rise in groundwater table, or rainfall. Similarly, many slopes that were stable for several years can abruptly fail due to changes in the slope geometry, weak soil shear strength, and external forces effect [1]. Long-run slope stability is associated with the chemical and weathering action that can reduce the soil's shear strength and produce tensional cracks. In these conditions, it is necessary to conduct slope stability analysis. The slope stability is determined based on the factor of safety (FOS). If the FOS is greater than 1 the resisting force due to shear strength of soil is higher than the driving force due to self-weight of the sloping ground and vice versa [2]. There are many methods to stabilize the slopes which are on the verge of failure (i.e. FOS $<1$ ). The soil nailing technique is one of them, in which the existing slope is reinforced with steel bars [3]. It is important that the interaction mechanism between soil and nails is understood, and the effects of the interaction on improving the slope stability are fully clarified. The estimation of nails' length and spacing forms the major part of the design procedure. It is widely known that the nail force, by friction or bond to surrounding soil, can decrease the principal strain in soil and hence improve the stability and decrease displacements.

Authors in [4] carried out numerical modeling to analyze slope stability. The mechanical parameters of soil layers constituting the slope were evaluated from laboratory results and numerical simulations of in-situ pressure meter tests. They concluded that the decrease of the mechanical parameters of the soil due to the increase in water content is the main cause of the slide. Authors in [5] conducted physical tests to investigate the behavior of unreinforced and soil nailed slopes under different static surcharge loads. The slopes were constructed of sand-sized soil at a presumed soil slope angle of $60^{\circ}$ with the horizontal plane. Different static loads were applied on the bearing plate mounted on the crest of the soil slope and the load settlement curve was observed. Nails inserted at $0^{0}$ were more efficient in providing stability to the slopes as compared to nails inserted at $15^{\circ}$ and $30^{\circ}$. Moreover, nails installed in staggered pattern were found to be most efficient. Authors in $[6,7]$ practiced with the limit equilibrium to study the three dimensional stability of slope for many cases. Limit equilibrium methods can be split up into 3 primary methods: slices, Swedish circle method (SCM), and methods for noncircular slip surface failure. There was not a thumb rule to 
define the safest technique, however it is generally accepted that noncircular analysis methods are safer. There is a common precept that the methods of noncircular failure are normally more reliable than other methods as they take the internal forces more cautiously. Many researchers accept that computed results are more or less equal $[8,9]$. Authors in [10] revealed that there are many uncertainties to the assessment of slope stability, and those associated with soil properties should be given particular attention. The uncertainty theory provides an alternative to treat these uncertainties using parochial cognitive sources. A novel methodology is proposed to evaluate the stability of slopes based on an uncertain set. Authors in [11] present a stability analysis of a high-steep rock slope with two faults during excavation and evaluate the effectiveness of a proposed reinforcement method using prestressed anchor cables. A 3D finite difference model was established based on the strength reduction method. The influence of various fault conditions and the effectiveness of the reinforcement on the slope stability during the excavation process were analyzed and compared to field monitoring data. They concluded that the displacement of the monitoring point gradually decreased after the reinforcement, and the deformation of the slope was effectively controlled. In this study, soil nail technique is proposed to upgrade the existing slope in clay. A parametric study was conducted to understand the effects of different nail diameter (i.e. $25 \mathrm{~mm}$ and $40 \mathrm{~mm}$ ) and nail inclination (i.e. $20^{\circ}$, $25^{\circ}, 30^{\circ}, 35^{\circ}$ and $40^{\circ}$ ) on slope stability. Optimized diameter and nail inclination were obtained to ensure slope stability.

\section{RESEARCH METHODOLOGY}

The slope stability in clay was investigated at an angle of $27^{0}$. Figure 1 shows the typical section of a slope in clay. The height and width of the slope were $10 \mathrm{~m}$ and $20 \mathrm{~m}$ respectively.

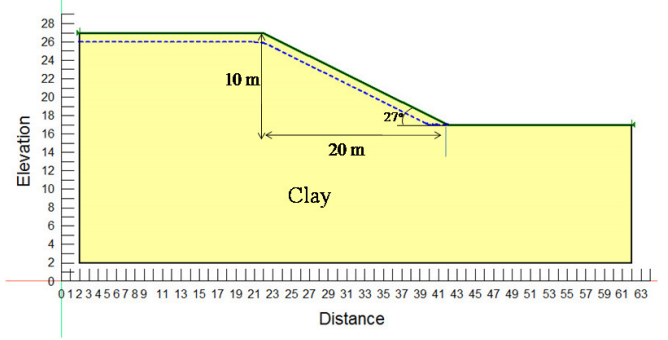

Fig. 1. Typical section of the slope in clay soil

\section{A. Criterion for Slope Stability}

The factor of safety of slope was determined by using the limit equilibrium method (LEM). Morgenstern-Price analysis procedure and half-sine function were adopted. Software package Slope/W was used for analysis. The safety factor, with respect to the stability of a slope, is generally defined as the ratio between shear strength, $\tau_{f}$ of the soil along a possible slip surface and the corresponding mobilized shear stress $\tau_{m o b}$ :

$$
F O S=\frac{\tau_{f}}{\tau_{m o b}}
$$

FOS can also be described in terms of either forces or moments acting on the soil mass. When $F O S=1$, the slope is in a state of impending failure. Generally, $F O S=1.5$ with respect to strength is acceptable for the design of a stable slope

\section{B. Soil and Nail Parameters}

The parameters of the soil slope (i.e. clay) were first defined and then assigned to the slope geometry. The MohrCoulomb failure criterion was used to model the clay. The input soil parameters required for the Mohr-Coulomb model are the unit weight of soil, the angle of internal friction and cohesion. Three rows of $2 \mathrm{~m}$ long soil nails with yield strength of $500 \mathrm{MPa}$ were used to upgrade the existing slope. Table I shows the Mohr-Coulomb soil parameters used in the SLOPE/W analysis.

\section{Numerical Modeling Procedure}

The numerical modeling procedure is summarised as:

1. Set the working area: scale and grid

2. Define the problem: choose Morgenstern-Price method

3. Sketch axes

4. Define soil properties: Mohr-Coulomb failure criterion

5. Draw boundaries of the problem: draw the top line and the bottom line from the leftmost point

6. Define pore water pressure conditions: draw piezometric line

7. Draw the slip surface radius: draw the area of points for slip surface and specify 20 for the radius increment

8. Draw the slip surface grid: draw the area and use 20 increments on each side.

9. Solve the problem

10. Post processing

TABLE I. SOIL SLOPE PROPERTIES

\begin{tabular}{|c|c|}
\hline Cohesion, $\boldsymbol{c}$ ' $(\mathbf{k P a})$ & 19 \\
\hline Friction angle, $\boldsymbol{\phi}\left({ }^{\circ}\right)$ & 20 \\
\hline Unit weight of soil, $\boldsymbol{\gamma}\left(\mathbf{k N} / \mathbf{m}^{\mathbf{3}}\right)$ & 15 \\
\hline
\end{tabular}

\section{RESULTS}

\section{A. Existing Slope Stability Analysis}

Limit equilibrium analysis method was carried on 9261 slip surfaces. The critical failure surface analysis result is shown in Figure 2. The minimum value of the FOS is 1.199. This implies that the slope in the existing soil condition is in a state of impending failure along the critical slip surface.

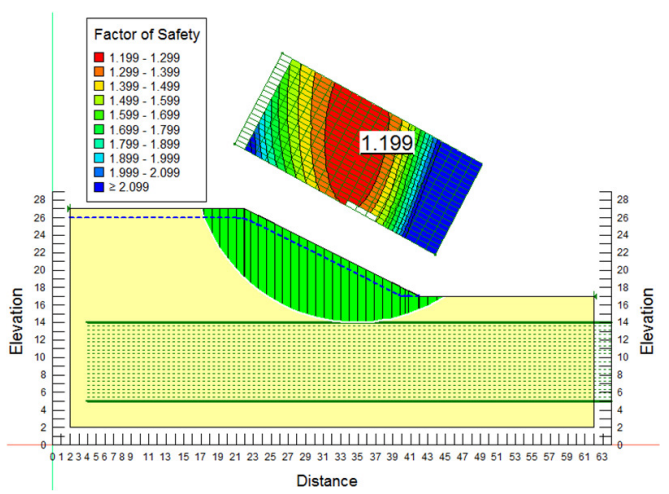

Fig. 2. Contours showing the existing slope's FOS 


\section{B. Upgradation of the Exisitng Slope Using Nailing Method}

The existing slope was upgraded by three rows of $20 \mathrm{~m}$ long soil nails with varying diameters $(25 \mathrm{~mm}$ and $40 \mathrm{~mm})$ and inclinations $\left(20^{\circ}, 25^{\circ}, 30^{\circ}, 35^{\circ}\right.$ and $\left.40^{\circ}\right)$.

\section{1) Upgradation with $25 \mathrm{~mm}$ Diameter Nails at $20^{\circ}$}

All possible slip surfaces for the upgraded slope with $25 \mathrm{~mm}$ diameter nails at $20^{\circ}$ are shown in Figure 3. It can be seen that the stability of slope has been improved slightly with minimum $F O S=1.446$ implying that the slope in the existing soil condition is in a state of impending failure along the critical slip surface.

\section{2) Upgradation with $25 \mathrm{~mm}$ Diameter Nails at $25^{\circ}$}

All possible slip surfaces for the upgraded slope with $25 \mathrm{~mm}$ diameter nails at $25^{\circ}$ are shown in Figure 4 . It can be seen that the slope stability has been improved slightly with minimum $F O S=1.457$. This implies that the slope in the existing soil condition is in a state of impending failure along the critical slip surface.

\section{3) Upgradation with $25 \mathrm{~mm}$ Diameter Nails at $30^{\circ}$}

All possible slip surfaces for the upgraded slope with $25 \mathrm{~mm}$ diameter nails at $30^{\circ}$ are shown in Figure 5. It can be seen that the slope stability has been improved slightly with minimum $F O S=1.461$. This implies that the slope in the existing soil condition is in a state of impending failure along the critical slip surface.

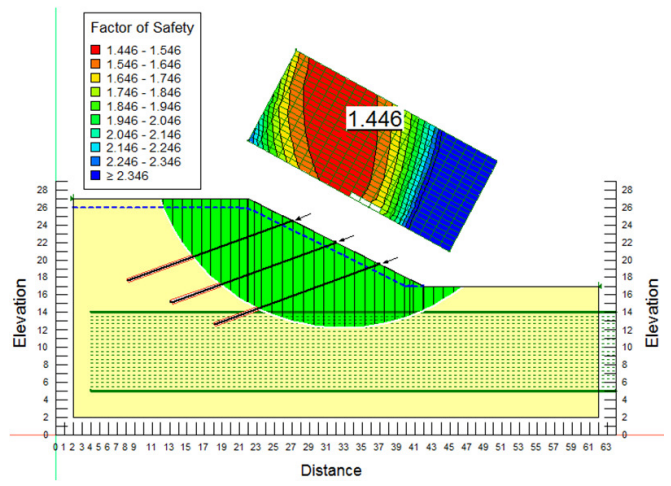

Fig. 3. Existing slope upgradation by three rows of $25 \mathrm{~mm}$ diameter nails at $20^{\circ}$

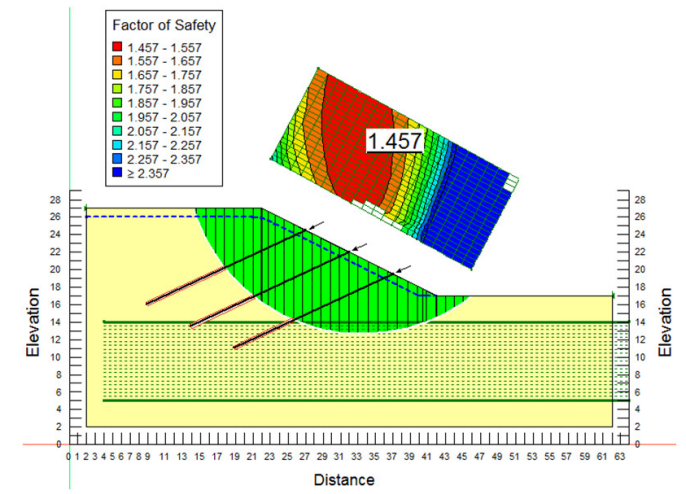

Fig. 4. Existing slope upgradation by three rows of $25 \mathrm{~mm}$ diameter nails at $25^{0}$

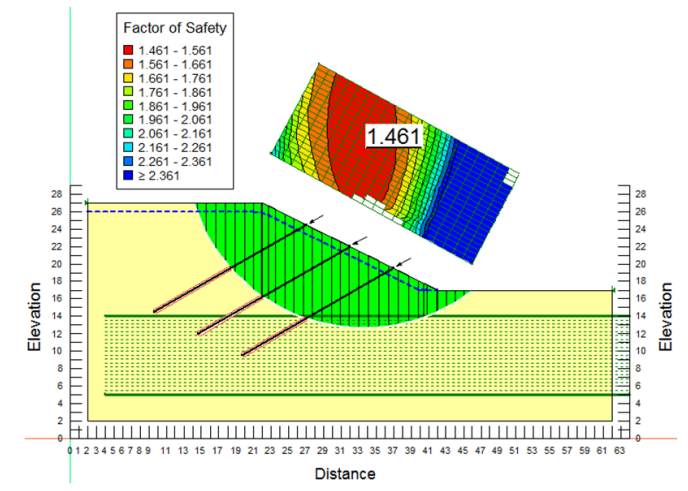

Fig. 5. Existing slope upgradation by three rows of $25 \mathrm{~mm}$ diameter nails at $30^{\circ}$

\section{4) Upgradation with $25 \mathrm{~mm}$ Diameter Nails at $35^{\circ}$}

All possible slip surfaces for the upgraded slope with $25 \mathrm{~mm}$ diameter nails at $35^{\circ}$ are shown in Figure 6. The stability of the slope has been improved slightly with minimum $F O S=1.460$. This implies that the slope in the existing soil condition is in a state of impending failure along the critical slip surface.

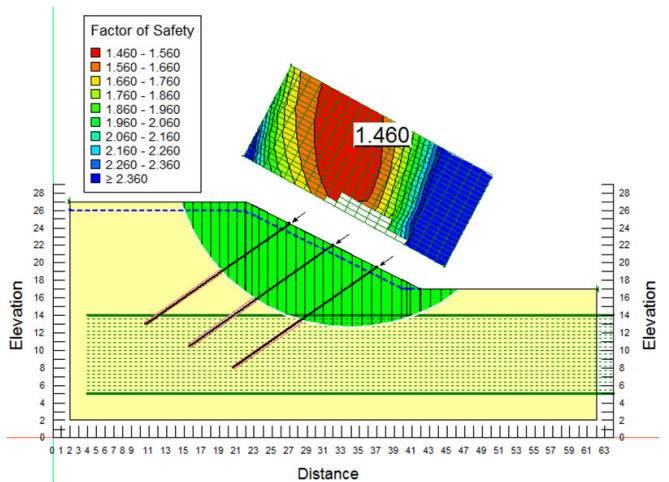

Fig. 6. Existing slope upgradation by three rows of $25 \mathrm{~mm}$ diameter nails at $35^{0}$

\section{5) Upgradation with $25 \mathrm{~mm}$ Diameter Nails at $40^{\circ}$}

All possible slip surfaces for the upgraded slope with $25 \mathrm{~mm}$ diameter nail at $40^{\circ}$ are shown in Figure 7 . The slope stability has been improved slightly with minimum $F O S=1.460$, implying that the slope in the existing soil condition is in a state of impending failure along the critical slip surface.

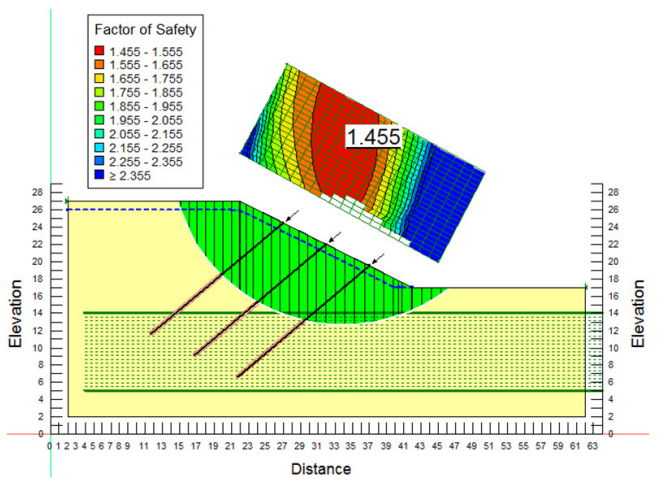

Fig. 7. Existing slope upgradation by three rows of $25 \mathrm{~mm}$ diameter nails at $40^{\circ}$ 


\section{6) Upgradation with $40 \mathrm{~mm}$ Diameter Nails at $20^{\circ}$}

All possible slip surfaces for the upgraded slope with $40 \mathrm{~mm}$ diameter nail at $20^{\circ}$ are shown in Figure 8. It can be seen that the slope stability has been improved significantly with minimum $F O S=1.521$. Considering the stability criterion of minimum $F O S=1.5$ the upgraded slope is in stable state.

\section{7) Upgradation with $40 \mathrm{~mm}$ Diameter nails at $25^{\circ}$}

All possible slip surfaces for the upgraded slope with $40 \mathrm{~mm}$ diameter nail at $25^{\circ}$ are shown in Figure 9. It can be seen that the stability of the slope has been improved significantly with minimum $F O S=1.566$, so the upgraded slope is considered to be in a stable state.

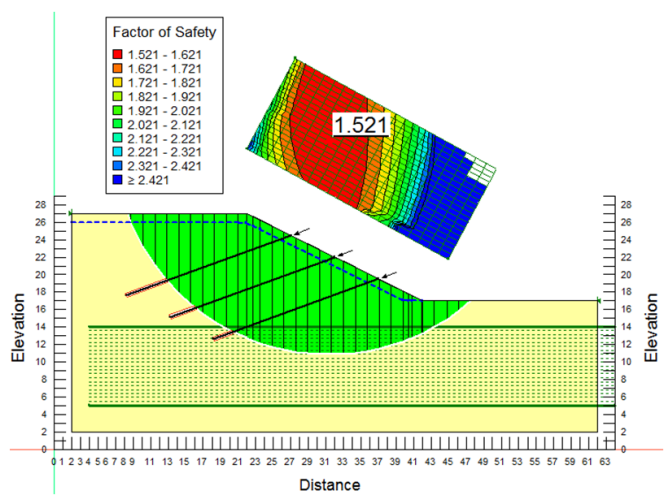

Fig. 8. Existing slope upgradation by three rows of $40 \mathrm{~mm}$ diameter nails at $20^{\circ}$

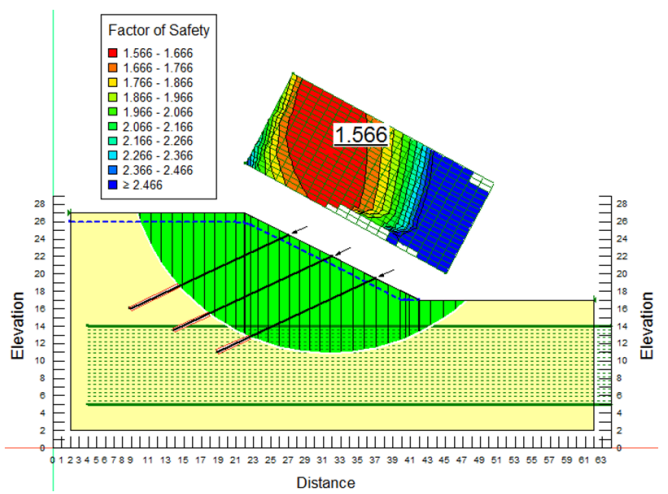

Fig. 9. Existing slope upgradation by three rows of $40 \mathrm{~mm}$ diameter nails at $25^{\circ}$

\section{8) Upgradation with $40 \mathrm{~mm}$ Diameter Nails at $30^{\circ}$}

All possible slip surfaces for the upgraded slope with $40 \mathrm{~mm}$ diameter nails at $30^{\circ}$ are shown in Figure 10. It can be seen that the stability of the slope has been improved significantly with minimum $F O S=1.610$ which is larger than the criterion of minimum $F O S=1.5$, so the upgraded slope is considered to be in stable state.

\section{9) Upgradation with $40 \mathrm{~mm}$ Diameter Nails at $35^{\circ}$}

All possible slip surfaces for the upgraded slope with $40 \mathrm{~mm}$ diameter nail at $35^{\circ}$ are shown in Figure 11. It can be seen that the stability of the slope has been improved significantly with minimum $F O S=1.643$ and the upgraded slope is in stable state.

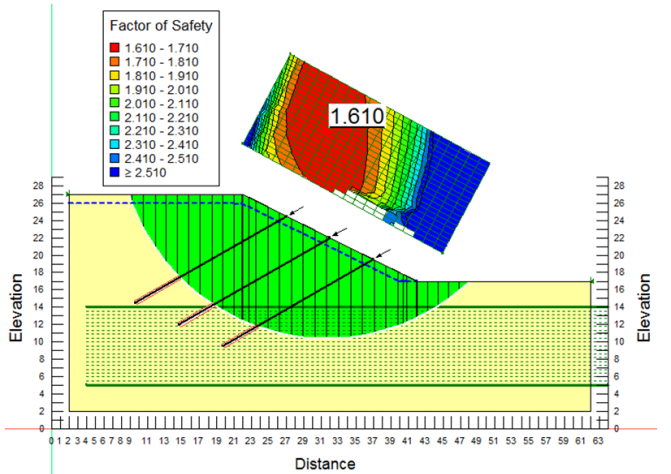

Fig. 10. Existing slope upgradation by three rows of $40 \mathrm{~mm}$ diameter nails at $30^{\circ}$

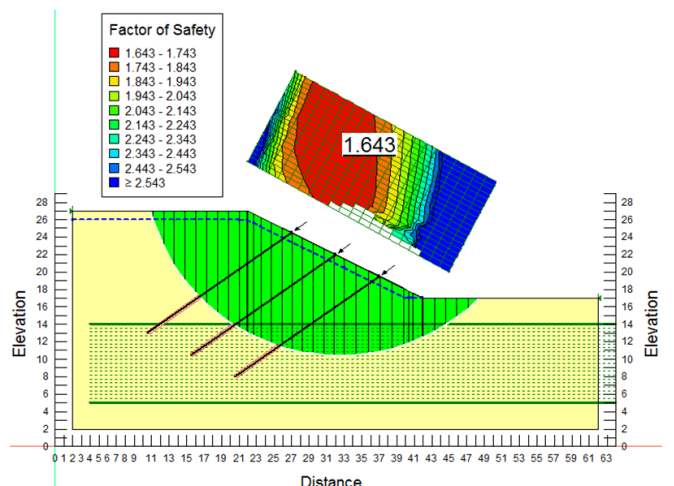

Fig. 11. Existing slope upgradation by three rows of $40 \mathrm{~mm}$ diameter nail at $35^{0}$

\section{0) Upgradation with $40 \mathrm{~mm}$ Diameter Nails at $40^{\circ}$}

All possible slip surfaces for the upgraded slope with $40 \mathrm{~mm}$ diameter nails at $40^{\circ}$ are shown in Figure 12. It can be seen that the stability of the slope has been improved significantly with minimum $F O S=1.668$.

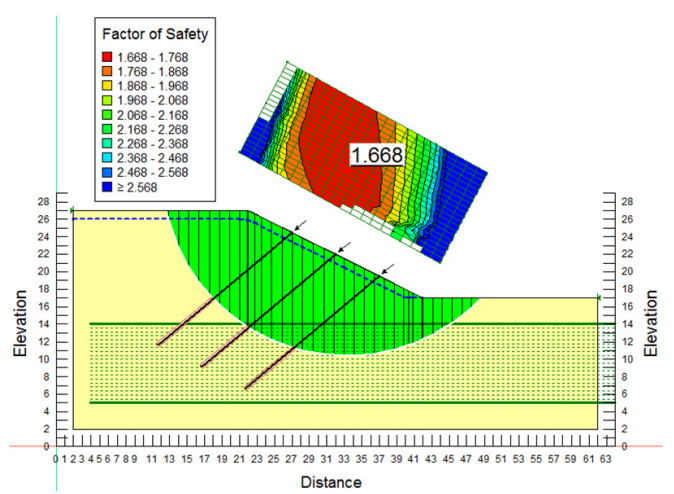

Fig. 12. Existing slope upgradation by three rows of $40 \mathrm{~mm}$ diameter nails at $40^{\circ}$

\section{Discussion}

In this study, soil nail technique was proposed to upgrade the existing slope in clay. A parametric study was conducted to understand the effects of nail diameter and nail inclination in slope stability in clay. Optimized diameter and nail inclination 
were obtained. The minimum factor of safety of the existing slope was computed as 1.119 with the help of limit equilibrium analysis. This value implied that the existing slope is likely to fail along the slip surface, since the minimum factor of safety is 1.5. Soil nail technique was used to upgrade the slope. It was observed that minimum FOS of the upgraded slope with $25 \mathrm{~mm}$ nail diameter at different inclinations did not meet the criterion of 1.5. The minimum factor of safety of the upgraded slope with $40 \mathrm{~mm}$ diameter nails was higher than 1.5 . It was found that the factor of safety of the existing slope improved significantly with three rows of $40 \mathrm{~mm}$ nails at an inclination of $40^{\circ}$. Table II summarizes the minimum FOS of the existing and upgraded slope with soil nails.

TABLE II. FOS OF EXISTING AND UPDRADED SLOPES SUMMARY

\begin{tabular}{|c|c|c|}
\hline Nail diam eter (mm) & Nail inclination $\left(^{0}\right)$ & FOS \\
\hline \multicolumn{3}{|c|}{ Existing slope } \\
\hline & & 1.199 \\
\hline \multicolumn{3}{|c|}{ Upgraded slope with soil nail } \\
\hline \multirow{5}{*}{25} & 20 & 1.446 \\
\hline & 25 & 1.457 \\
\hline & 30 & 1.461 \\
\hline & 35 & 1.460 \\
\hline & 40 & 1.455 \\
\hline \multirow{5}{*}{40} & 20 & 1.521 \\
\hline & 25 & 1.566 \\
\hline & 30 & 1.610 \\
\hline & 35 & 1.643 \\
\hline & 40 & 1.688 \\
\hline
\end{tabular}

\section{CONCLUSION}

Based on the slope stability analysis results of the soil nailing technique, the following conclusions can be drawn:

- The value of minimum FOS of the existing slope in clay was computed to be 1.199 . This means that the existing slope was not stable.

- The existing slope was upgraded by three rows of nails of $25 \mathrm{~mm}$ and $40 \mathrm{~mm}$ diameter at different inclinations.

- The minimum FOS improved slightly, but was less than the stability criterion of 1.5 with the $25 \mathrm{~mm}$ diameter nails at all inclinations.

- With the $40 \mathrm{~mm}$ diameter soil nails, the minimum FOS improved significantly. Thus, nails of $40 \mathrm{~mm}$ diameter were effective and increased FOS significantly compared to nails with $25 \mathrm{~mm}$ diameter.

\section{REFERENCES}

[1] P. Ghosh, A. Biswas, "Effect of Reinforcement on Stability of Slopes using GEOSLOPE", International Conference on Benchmarks in Engineering Science and Technology, Maharashtra, India, September 78,2012

[2] M. A. Hossain, A. Islam, "Numerical analysis of the effects of soil nail on slope stability", International Journal of Computer Applications, Vol. 141, No. 8, pp. 12-15, 2016

[3] J. Zhang, L. M. Zhang, W. H. Tang. "New methods for system reliability analysis of soil slopes", Canadian Geotechnical Journal, Vol. 48, No. 7, pp. 1138-1148, 2011
[4] A. Fawaz, E. Farah, F. Hagechehade, "Slope Stability Analysis Using Numerical Modelling", American Journal of Civil Engineering. Vol. 2 , No. 3, pp. 60-67, 2014

[5] S. Singh, A. K. Shrivastava, "Soil nailing for stability of the slopes", International Journal for Research in Applied Science \& Engineering Technology, Vol. 5, No. 10, pp. 752-763, 2017

[6] S. B. Mickovski, F. M. Lindsay, M. J. Smith. "Construction and testing of self-drilled soil nails", Proceedings of the Institution of Civil Engineers-Geotechnical Engineering, Vol. 169, No. 6, pp. 541-553, 2016

[7] S. H. Jiang, D. Q. Li, L. M. Zhang, C. B. Zhou, "Slope reliability analysis considering spatially variable shear strength parameters using a non-intrusive stochastic finite element method", Engineering Geology, Vol. 168, pp. 120-128, 2014

[8] X. L. Chen, C. G. Liu, Z. F. Chang, Q. Zhou, "The relationship between the slope angle and the landslide size derived from limit equilibrium simulations", Geomorphology, Vol. 253, pp. 547-550, 2016

[9] K. Lim, A. J. Li, A. V. Lyamin, "Three-dimensional slope stability assessment of two-layered undrained clay", Computers and Geotechnics, Vol. 70, pp. 1-17, 2015

[10] X. Zhou, J. Li, Z. Liu, Y, Tang, "Analysis of slope stability with imprecise soil properties using uncertain sets", Mathematical Problems in Engineering, Vol. 2019, Article ID 1062347, 2019

[11] Q. Zhan, X. Sun, C. Li, Y. Zhao, X. Zhou, Y. He, Y. Zhang, "Stability analysis and reinforcement of a high-steep rock slope with faults: numerical analysis and field monitoring", Advances in Civil Engineering, Vol. 2019, Article ID 3732982, 2019 